\title{
Technological Growth and Economic Geography
}

\author{
Giovanni Peri*
}

Preliminary Draft: November 1998

Comments very welcome

\begin{abstract}
The literature pioneered by Krugman (1991a) now known as "New economic geography" has developed very insightful models to understand phenomena as the agglomeration of economic activity and the specialization of regions. Nevertheless I think that the emphasis on the process of specialization, has been somewhat misleading both at a theoretical and empirical level. The attention of the literature has been focused on decreasing transport costs as the unique engine of the process. I develop a modified version of such models in which technological knowledge and its growth and spillovers are important forces at work, once agglomeration has taken place. I obtain the interesting result that after the dramatic tendency to specialization, driven by decreasing transport costs, local technological growth generates a tendency towards de-specialization, in the most advanced regions. This pattern fits the stylized facts relative to the last 40 years in the U.S. There, after a strong tendency towards industrial concentration, there has been a tendency, towards deconcentration. A first look at the data for European countries, for the last 30 years also shows a tendency to constant or slightly decreasing concentration of industries and de-concentration of innovative activity.
\end{abstract}

\footnotetext{
“ IGIER and Universita' L.Bocconi. Please send comments to giovanni.peri@uni-bocconi.it. I am grateful to Sofia Berto for her help with the data.
} 


\section{Introduction}

One of the most dramatic facts in the world economy of the last 30 years has been the growth of technological knowledge and its application to the production process (information technologies, bio-engineering and so on). Another has been the increasing integration of the world economies, thanks to the decrease in trade barriers, at least among developed countries, with the resulting increase in international trade. One of the most notable intellectual event in the field of economics in the last 10 years, has been the (re) introduction of economic growth and economic geography as central disciplines in the understanding of cross countries differences, productive specialization and productivity growth. This paper takes it from there and gives a contribution to the understanding of the effect of decreasing transport costs and technological growth on inter-regional specialization and de-specialization, using a "new geography model".

One simple stylized fact, that has been observed since the last century (Marshall 1890) and has been confirmed by historical (Kim 1995) as well as rigorous econometric analysis (Ellison and Glaeser 1997), is that the industrial production tends to be geographically localized and regions tend to be specialized. Regions, that is, do not tend to develop a balanced range of industrial productions but specialize in one industry or few related ones. It is hard to tell if this phenomenon is driven by classic comparative advantages (factors endowments) or by local external economies. Recent work (Davis 1998, Davis and Weinstain 1998 and Davis, Weinstain and Shimpo 1997) finds that international specialization is mainly determined by factor endowment, while inter-regional specialization may be importantly influenced by external economies and increasing returns.

Nevertheless in this general tendency towards specialization and agglomeration there is also a second stylized fact, sometimes ignored, but rather well established in the empiric literature in economics (Fuchs 1962, Hoover 1971, Krugman 1991b, Kim 1995) as well as in geography (Scott 1988). In the last 40 years in the US regions, the general tendency has been towards a decrease in the degree of industrial specialization. Using the simple index of regional specialization and localization proposed by 
Krugman 1991b ${ }^{1}$, Kim 1995 finds that the degree of regional specialization has been steadily decreasing in US states since 1950. For European countries, the evidence is much less clear cut, because the availability of the data is more limited. I use the Unido Industrial Statistic Database to construct some indices relative to industrial specialization of European countries from 1967 to 1992. I find no tendency to increased specialization on average, and for smaller countries a tendency towards despecialization. The initial period of industrialization in the US and Europe (end of last century, beginning of this century) has coincided with a dramatic increase in the agglomeration of economic activity and specialization (see De Vries 1984) . The last 40 years have been characterized by a decreasing degree of specialization, in the US, and by a rather constant level of specialization in Europe, where integration is still on its way.

The seminal findings on this topic in Krugman (1991 b) have, I think, misguided the following research. The idea that Europe is less regionally specialized than the U.S., and that this depends on the strong agglomeration happened in the U.S. is if we re-consider the stylized facts, not a good way to summarize the story.

The goal of this paper is to use a modified version of the Krugman and Venables (1996) model to understand how a pattern of early specialization, and later de-specialization may be generated by a plausible story on transport cost and technological growth. The existing models of economic geography have done incredible progresses in understanding specialization and agglomeration. Their limit is that they consider only transport costs as the main actor in the story, and therefore have a hard time in explaining de-specialization in advanced economies. This model, with very standard ingredients (demand and cost linkages, monopolistic competition, factor neutral technological progress) produces an interesting and surprising result that can be summarized in the following story.

As the transport costs decline, the initial situation of de-specialized economic activity, where all regions produce many goods, becomes unstable, as cost linkages tend to increase the benefits of localizing one industry in one place. This process generates at some point a phenomenon of "catastrophic" agglomeration, which

${ }^{1}$ The formula proposed is $S I_{j k}=\sum_{i=1}^{n}\left|\frac{E_{i j}}{E_{j}}-\frac{E_{j k}}{E_{k}}\right|$ where $\mathrm{E}_{\mathrm{ij}}$ is the level of employment in industry 
historically can be considered as the huge increase in urbanization and specialization that took place in the U.S. at the end of the last century ${ }^{2}$. At this point the clustering of industries generates technological growth especially in those regions where are clustered industries with high technological content. If local growth of technology and productivity may spill to other sectors in the region this grant to the region a technological leadership. At some point, the temptation of some workers in the region to use their technological lead to produce more efficiently also in the other sector will generate tendencies towards spin-off in the other industries and towards a reduction of the specialization. The "advanced regions" will tend to de-specialize while the other regions will still remain more specialized.

This story is fundamentally different from one as in Puga and Venables (1998), where the de-specialization is driven by relocation of production in regions where labor is cheaper (fit to explain de-localization towards less developed countries). Here despecialization is generated by spin-offs in other sectors that use technological advantages to profit in the new market (more appropriate to explain regional despecialization in more advanced countries)..

The paper is organized as follows, section 2 summarizes and organizes some stylized evidence. It reconsiders the story in Krugman 1991b and describes the pattern of specialization, in the US and Europe. Section 3 introduces the model in its baseline version. Section 4 adds disembodied technological progress and shows the different historical evolutions that could be generated by different types of technological spillovers. Section 5 provides a simple welfare analysis. Section 6 concludes the paper illustrating the potential extensions.

\section{A Closer Look at the Stylized Facts}

\footnotetext{
$i=1, \ldots n$ for region $j$ and $E_{j}$ is the total industrial employment for region $j$.

${ }^{2}$ In various European countries this phase took place in the last century or at the beginning of this century.
} 


\subsection{Krugman's story revisited}

The first stylized fact reported by Krugman 1991b, to exemplify the role of "transport cost" in a broad sense, was the comparison of specialization of the U.S. region versus the European regions. The table, reported below, represents the bi-lateral specialization index, for four American regions and four European countries computed as follows:

$$
S_{j k}=\sum_{i=1}^{n}\left|\frac{E_{i j}}{E_{j}}-\frac{E_{i k}}{E_{k}}\right|
$$

where $E_{i j}$ is the level of employment in industry I for region $j$ and $E_{j}$ is the total industrial employment for region $\mathrm{j}$. If the index is equal to zero then the two regions are completely de-specialized. If it is equal to two they are completely specialized.

\begin{tabular}{lllll}
\hline $\begin{array}{l}\text { U.S. Regions } \\
\mathbf{1 9 7 7}\end{array}$ & NE & MW & S & W \\
\hline NE & - & .224 & .247 & .242 \\
\hline MW & - & - & .336 & .182 \\
\hline S & - & - & - & .271 \\
\hline
\end{tabular}

\begin{tabular}{lllll}
\hline $\begin{array}{l}\text { EC Countries } \\
\mathbf{1 9 8 5}\end{array}$ & Fra & FRG & Ita & UK \\
\hline Fra & - & .200 & .197 & .083 \\
\hline Frg & - & - & .175 & .184 \\
\hline Ita & - & - & - & .184 \\
\hline
\end{tabular}

Source: Krugman 1991b, pag. 77

As you see from the years to which the data are referred, the U.S. specialization index is calculated eight years before the European one. This makes a 
difference, due to the de-specialization trend of the U.S. in the last 40 years. If we compare the numbers for 1986 in the U.S., calculated from the Kim's (1995) data, we find the following indices for the U.S. regions.

\begin{tabular}{lllll}
\hline $\begin{array}{l}\text { U.S. Regions } \\
1986\end{array}$ & NE & MW & S & W \\
\hline NE & - & .194 & .214 & .210 \\
\hline MW & - & - & .292 & .158 \\
\hline S & - & - & - & .235 \\
\hline
\end{tabular}

Source: my calculations on Kim's 1995 data

The comparison of these numbers with the values for European countries does not reveal a dramatic difference in specialization. Two indices are larger for the European Countries, two are larger for the U.S. by less than $30 \%$ and only two of them are larger for the U.S. by more than $30 \%$. Moreover as we will see considering the evolution of specialization in the last 30 years these values are the result of a process of de-specialization of the U.S., without any dramatic move towards specialization of Europe, even in the year of increased integration (1980-1990). This fact must induce a more careful consideration of the phenomenon of de-specialzation, which has been almost forgot in the economic geography literature.

\subsection{United States}

The evidence here considered is the historical evidence and some anecdotal evidence on the behavior of industrial specialization in regions of the US. The main fact stressed by economic geography in the analysis of the specialization of the US versus Europe is the higher degree of regional specialization of the first economy relative to the second, as we have said above (Krugman 1991b, Krugman and Venables 1995). What has not been considered in particular detail is the fact that during the last 40 years the regional economies of the United States have experienced a strong 
decrease in their degree of specialization. If we calculate the bilateral index of regional specialization (defined in the previous section) for the nine census regions, as done in Kim (1995) this will tell us for each pair of region how their sector composition is similar (de-specialized) or dissimilar (specialized).

If we calculate the index for all couple of regions and take an average, we have a general index of regional specialization for the whole U.S. The evolution of such index, relative to two digit manufacturing sectors., in the last 100 years is shown in Figure I, taken from Kim (1995). The tendency to specialize towards the end of the last century, beginning of this century is very clear, as it is the tendency to de-specialize in the last 30 years. Similar message is given if we calculate the index of localization of industries as :

$$
L_{i j}=\left(\frac{E_{i j} / E_{i U S}}{E_{j} / E_{U S}}\right)
$$

where $E_{i j}$ and $E_{I}$ are defined as before $E_{i U S}$ is total employment in sector $i$ for the whole country and $\mathrm{E}_{\mathrm{US}}$ is the total employment. If we calculate for each sector a Gini coefficient of the indices of localization across regions, we have a measure of the dispersion of that industry across the regions. Averaging across the industries (2-digit manufacturing sectors) we obtain a summary measure of the localization of US manufacturing Sector. Figure II, show the same type of behavior of the previous index, concentration at the beginning of the century, de-concentration in the last 40 years.

\subsection{Europe}

The evidence on Europe is less developed. There are, in fact very few data on historical tendencies of specialization. The ideal statistics that I would like to know are the specialization of different regions (at the Nuts 2 level) but no historical track of it seem to be recorded. For the recent characteristics an interesting finding is in Paci and Usai 1998. They find a positive correlation between the diversity of the manufacturing sector and labor productivity for 120 European regions. Moreover the sectoral 
diversity of innovative activity is also correlated with the level of labor productivity ${ }^{3}$. A second interesting stylized fact can be found in Breschi and ***** (1998). They find a strong tendency of the patenting (innovative) activity to increase its spatial dispersion among European counties in the eighties. As we will see these could be an important suggestion that the model we develop is capturing a relevant feature of the despecialization process. The statistics that I have calculated are relative to the Herfindal index of sectoral agglomeration in 12 European country and its average at the European level. The Herfindal index is calculated as follows:

$$
H_{i}=\sum_{j=1}^{n}\left(s h_{i j}\right)^{2}
$$

where $\mathrm{sh}_{\mathrm{ij}}$ is the share of employment in industry $\mathrm{j}$ for country $\mathrm{i}$.

The Data are relative to 25-30 years in the period 1963-1992, their availability varies by country. The source is the UNIDO Industrial Statistics Data Base and I got the data on Employment, by country for the 3-digit ISIC classification (see appendix A for the list of sectors $)^{4}$. Looking at the plot for the European average ( Figure IV) no tendency towards specialization emerges. If we consider that the emphasis for the last 20 years has been on increased integration of the economies, and lower transport costs, we do not see the specialization that should emerge if the break point is passed. More likely those economies have already passed the level of "catastrophic agglomeration" and are now maintaining the specialization arisen in the past. Considering single countries the behavior are different, with smaller countries showing tendency towards de-specialization and larger countries on a flat profile or mildly specializing (Figure III). Overall we have a portrait of increasing specialization at the beginning of the century, and flat or decreasing specialization thereafter for two of the most industrialized economies in the world. Moreover the tendency to de-specialize seem to be more accentuated where the productivity of labor is higher and is accompanied by a tendency to increase the sectoral dispersion of innovative activity. We will present a model that offers a possible insight in this phenomenon.

\footnotetext{
${ }^{3}$ Paci and Usai 1998 find a 0.45 significant correlation between dispersion in manufacturing sectors and labour productivity.

${ }^{4}$ I thank Sofia Berto for her help in localizing and mading the data available.
} 


\section{The Model}

\subsection{Basic Specification and the industrial structure}

The model that I will develop to analyze the process of industrial specialization and de-specialization, is inspired by the one developed by Krugman and Venables (1996). It is a model with two regions, two sectors and only one production factor (Labor), which is assumed do be mobile between sectors in one region. Labor responds to wage differentials between sectors moving towards the sector that pays higher wages. Mobility across region is not allowed. In the baseline model it will not arise in equilibrium as the wage paid in the two regions are the same. In the modified model, which is of interest for us, a wage differential arises between regions but we assume that there are some obstacles to migration. In short, mobility between sectors is larger than between regions, consistently with what found in Peri (1998).

Each of the two sectors produces a range of different goods, and for each good there is a single producer acting as monopolist, as there is a fixed cost of starting up production $^{5}$, which is paid in units of the produced good. The production of each good requires the use of labor, the use of all goods of the same sector and of all goods of the other sector as intermediate inputs, in the form of a composite intermediate good. If we index the two sectors with 1 and 2, the composite good is described by:

$$
X_{j}=\left[\int_{1}^{n} x(i)^{\frac{\sigma-1}{\sigma}} d i\right]^{\frac{\sigma}{\sigma-1}} \quad j=1,2
$$

The elasticity of substitution is therefore constant across varieties and is the same between the two industries equal to $\sigma$. The same composite good is also consumed by people who spend the same share of income in each good. Their utility function is given by: 


$$
U=X_{1}^{0.5} X_{2}^{0.5}
$$

The key assumption that drives the process of concentration, when transport costs decrease, is that the production function of each good uses more intensively the intermediate inputs from the same sector than those of the other sector. The matrix input-output that summarizes the share of total cost paid by each sector to each input of the production is as follows:

\begin{tabular}{|l|l|l|}
\hline Input / Output & Sector 1 & Sector 2 \\
\hline Sector 1 & $\alpha$ & $\gamma$ \\
\hline Sector 2 & $\gamma$ & $\alpha$ \\
\hline Labor & $\beta$ & $\beta$ \\
\hline
\end{tabular}

Where $\alpha>\gamma$.

In technical notation the production function for each good, assuming that the fixed cost is incurred in units of the good itself and is equal to F and assuming linear homogeneity in the variable costs is:

$$
x(i)_{j}=\left(\frac{\left(l(i)_{j}^{\beta} X_{j}^{\alpha} X_{k}^{\gamma}\right)-F}{B}\right) \quad \mathrm{j}, \mathrm{k}=1,2
$$

where $\mathrm{B}$ is a constant to re-scale the production units.

From these assumptions follow that the demand faced by each producer of a variety has the following easy form:

\footnotetext{
${ }^{5}$ The monopolistic competition model used is a variation of the Dixit and Stiglitz (1977), as can be found in all the model of "new geography" (see Fujita, Krugman and Venables 1998)
} 


$$
x(i)_{j}=\left(\frac{p(i)_{j}}{G_{j}}\right)^{-\sigma} \frac{E_{j}}{G_{j}} \quad j=1,2
$$

where $E j$ is the total spending in varieties of sector $j$ and $G j$, the price index for the composite good $\mathrm{X}_{\mathrm{j}}$, is given by:

$$
G_{j}=\left[\int_{0}^{n} p(i)_{j}^{1-\sigma}\right]^{\frac{1}{1-\sigma}} \quad j=1,2
$$

Expression (4) has an intuitive interpretation: The demand for a variety produced by sector $\mathrm{j}$ decreases when its price, relative to the price index of the whole sector, increases. On the other side, the demand increases when the real expenditure in products of that sector increases. The profit maximizing choice of price, by the monopolists, implies a mark-up on unit costs, given the constant elasticity demand. As the mark-up depend on B (re- scaling factor) we can choose units so that the optimal price is equal to unit costs. Using the symmetry of the condition for each variety in one industry we can write the price equal unit costs as follows:

$$
p_{i}=w_{i}^{\beta} G_{i}^{\alpha} G_{j}^{\gamma} \quad \text { for } \quad i, j=1,2
$$

\subsection{Transport costs and determination of price and wages}

The key conditions (4) and (5) have been written for the case of one country and no transportation costs. Let's now assume that there are iceberg costs to transport gods between regions and that they are equal for each sector. These costs take the usual form that, when shipping one unit of good from one region, only $1 / \mathrm{T}$ arrives to the other. In this case only some varieties for each sector will be produced in each region and the price indices $G_{1}$ and $G_{2}$ will be different in the two regions. All varieties produced in a region, though, will have the same price. Defining $n_{1}$ and $n_{2}$ the number 
of varieties produced in one region and denoting with the asterisk all the variables relative to the other region, equation (4) gives the following conditions:

$$
\begin{aligned}
& G_{1}=n_{1} p_{1}^{1-\sigma}+n_{1}^{*}\left(p_{1}^{*}\right)^{1-\sigma} T^{1-\sigma} \\
& G_{2}=n_{2} p_{2}^{1-\sigma}+n_{2}^{*}\left(p_{2}^{*}\right)^{1-\sigma} T^{1-\sigma}
\end{aligned}
$$

and symmetric conditions for the price index relative to the other region.

Recall, now that in each region workers can choose to work in either sector. Standardizing the total population of each region to 1 and calling $\mathrm{L}_{1}\left(\mathrm{~L}_{2}=1-\mathrm{L}_{1}\right)$ and $\mathrm{L}_{1}{ }^{*}$ $\left(\mathrm{L}_{2}{ }^{*}=1-\mathrm{L}_{1}{ }^{*}\right)$ the fraction of workers in sector one (two), we have that the total wage bill in sector i must be: $\mathrm{w}_{\mathrm{i}} \mathrm{L}_{\mathrm{i}}=\beta\left(\mathrm{n}_{\mathrm{i}} \mathrm{p}_{\mathrm{i}} \mathrm{q}_{\mathrm{i}}\right)$. Choosing the firm scale as $\mathrm{q}=1 / \beta$, equal for all sectors and regions, we have the simplification $\mathrm{w}_{\mathrm{i}} \mathrm{L}_{\mathrm{i}}=\mathrm{n}_{\mathrm{i}} \mathrm{p}_{\mathrm{i}}$.

We use this equality in the expression of the demand for a variety (5), which is now given by the sum of the demand from the same region plus the demand from the other region, inclusive of transport costs. After some manipulation we get:

$$
\begin{aligned}
& \left(w_{1}\right)^{\beta}\left(G_{1}\right)^{\alpha}\left(G_{2}\right)^{\gamma}=\beta\left[\left(G_{1}\right)^{\sigma-1} E_{1}+\left(G_{1}^{*}\right)^{\sigma-1} E_{1}^{*} T^{1-\sigma}\right] \\
& \left(w_{2}\right)^{\beta}\left(G_{2}\right)^{\alpha}\left(G_{1}\right)^{\gamma}=\beta\left[\left(G_{2}\right)^{\sigma-1} E_{2}+\left(G_{2}^{*}\right)^{\sigma-1} E_{2}^{*} T^{1-\sigma}\right]
\end{aligned}
$$

and two symmetric expressions for the other region.

$E_{i}$ is the expenditure from one region in good of sector $i$, while $E_{i}^{*}$ is the expenditure from the other region in goods of sector $i$. Their expression is the sum of expenditure on the goods by final consumers and by the purchaser of intermediate products.

$$
E_{1}=\frac{w_{1} L_{1}+w_{2} L_{2}}{2}+\frac{\alpha w_{1} L_{1}+\gamma w_{2} L_{2}}{\beta}
$$




$$
E_{2}=\frac{w_{1} L_{1}+w_{2} L_{2}}{2}+\frac{\gamma w_{1} L_{1}+\alpha w_{2} L_{2}}{\beta}
$$

If we eliminate the prices $p$, and the number of varieties $n$ from equations (7) and (8), we get the following two equations (plus two symmetric for the other region) that complete our set of conditions:

$$
\begin{aligned}
& G_{1}=L_{1} w_{1}^{1-\beta \sigma}\left(G_{1}\right)^{-\alpha \sigma}\left(G_{2}\right)^{-\gamma \sigma}+L_{1}^{*}\left(w_{1}^{*}\right)^{1-\beta \sigma}\left(G_{1}^{*}\right)^{-\gamma \sigma}\left(G_{2}^{*}\right)^{-\alpha \sigma} T^{1-\sigma} \\
& G_{2}=L_{2} w_{2}^{1-\beta \sigma}\left(G_{2}\right)^{-\alpha \sigma}\left(G_{1}\right)^{-\gamma \sigma}+L_{2}^{*}\left(w_{2}^{*}\right)^{1-\beta \sigma}\left(G_{2}^{*}\right)^{-\gamma \sigma}\left(G_{1}^{*}\right)^{-\alpha \sigma} T^{1-\sigma}
\end{aligned}
$$

Equation (9) and (10) determine for each level of the price indices and of the distribution of workers in the two sectors, the wages that allow firms to break even, that is to cover their fixed cost. This condition is very important. In this framework, in fact, although each monopolist has some market power, she will not make any profit. The free entry of new firms in the industry will force each producer to price at its unit costs. Equation (13) and (14) determine the level of prices for each sector in each region. We can see that the price index in each region for each sector depends on all four price indices. This creates a link in the price of all goods.

It is not straightforward to understand how four prices and four wages will interact, to determine an equilibrium allocation of workers in the two sectors in each country. Nevertheless we will use some insight from the symmetry of the problem and some simulation techniques to understand the dependence of specialization on transport costs.

\subsection{Break Points and Sustain Points}


The model written above may support two types of equilibria, depending on the level of transport costs. The reason why this happens is very simple. At high level of transport costs, each sector serves a local market. Consumers in the region guarantee a level of demand for each good that makes it convenient to have both sectors located in both markets to satisfy local demand. When transport costs start declining it becomes possible to serve the market from one location, if higher concentration of producers in the same sector decreases the cost of intermediates. Therefore at some point the symmetric equilibrium will be broken in what is called a "catastrophic dynamic", as the system will tend to collapse towards agglomeration of each industry in one region. The illustration of this process is well understood if we consider a representation of the real wages as a function of the share of workers in each sector for each country. Figure 1, 2 and 3 represent the real wages in one region as a function of the share of workers in the industry. Given the symmetry of the model the plot represents the wages in sector 1 and 2 measured as function of workers in sector 1 (sector2) in the first (second) region. We have chosen three values of transport costs, that illustrate the effect of a decrease from high level, (costs are sixty percent of the transported values) to lower (45\%) and lower $30 \%$ levels. It is clear that while originally the only stable equilibrium is the one where the two regions are equally balanced in their production, with the decrease in transport costs the possibility of a "concentrated equilibrium" arises. For intermediate levels of transport costs, we have that both concentration and diffusion are locally stable. For low transport cost the only stable equilibrium is agglomeration. The table are drawn for values of the parameters, similar to those used in the previous literature (Krugman and Venables 1996, Puga and Venables 1997), assuming that linkages within a sector are four times stronger than linkages across sectors.

An important concept, which we will define on this section and that will play a crucial role in the model augmented to incorporate technological progress, is what we call "temptation of a spin-off in the other sector". In this model we assume that workers are also the enterpreneurs who decide to create a new monopolistically competitive firm. They will therefore create a new firm in the other sector if the real wage that they get in this new activity is larger that the one they get in the old sector. At the concentration point, if we assume sector 1 concentrated in the first region, the "temptation" will be given by $\left(\mathrm{w}_{2} / \mathrm{w}_{1}\right)$ calculated at $\mathrm{L}_{1}=1$ and $\mathrm{L}_{1}{ }_{1}=1$.

This expression after several simplifications becomes as follows: 


$$
\left(\frac{w_{1}}{w_{2}}\right)^{\beta \sigma}=T^{(\gamma-\alpha) \sigma}\left[\frac{1+\gamma-\alpha}{2} T^{\sigma-1}+\frac{1+\alpha-\gamma}{\beta} T^{1-\sigma}\right]
$$

For the chosen values of technological parameters, the "temptation of the spinoffs" is plotted in Figure 4. Clearly the specialized equilibrium can be sustained only for lower values of $\mathrm{T}$, when the term in (15) does not exceed 1. For all transport costs smaller than the intersection between the curve and the line $\left(\mathrm{W}_{2} / \mathrm{W}_{1}\right)=1$ we have that the temptation to spin-off in the other sector is not strong enough so that the concentrated equilibrium is maintained.

Finally we can illustrate the profile of concentration in the two sectors and the real wages in the two countries as a function of the transport costs. This is what is shown in Figure 5 and 6. The pictures show an important feature. Starting from high transport costs and moving towards lower costs, nothing happens until a critical value is reached. At that value the agglomerating forces due to backward linkages become stronger than the "isolating" effect of transport costs, and the production tends to experience a catastrophic agglomeration. This story seem to be a plausible explanation for the strong tendency towards concentration experienced at the beginning of our century in many countries. Nevertheless if this is the whole story the there would be a persistence of this pattern as transport costs keep decreasing, or, at some point reach some lower limit and remain unchanged. Introducing some technological progress, in a very easy form, we are able to understand also the rest of the story, that leads to deconcentration.

\section{Effects of Disembodied Technological Progress}

In this section I introduce a realistic assumption, derived from the stylized facts and the empirical findings emerged in the last years of research. The assumption is that, although industrial agglomeration may have arisen mainly for demand and cost 
linkages, these agglomeration generate positive knowledge externalities. Jaffe, Henderson and Trajtenberg (1992), find that innovation spillovers, as captured by patent citations, are geographically localized. Glaeser et al (1992), Henderson, Kunoco and Turner 1995, find evidence that in cities there are dynamic externalities, due to knowledge spillovers. I do not intend in this paper to model thoroughly the process of local technological spillovers, or the process of technological growth. I simply want to analyze the consequences of different types of technological progress, on industrial concentration.

In particular I will analyze what happens when technological growth, absent before industrial concentration, arises when concentration is triggered. The effects of technological growth will be analyzed as any change in an exogenous parameter in these type of models. We will distinguish though among different structure of knowledge spillovers. In one case progress will be industry and region specific, in one case it will be industry-specific and in the last case it will be region specific.

The result are rather different. In the first case we have the usual effect of technological lock-in, with one region increasing its technological advantage in one industry (Krugman 1986). In the second case we have that the product which will experience technological growth in its production will become cheaper and will be produced in larger quantities, but the localization of production will not change. In the third, and most interesting case, the region where technological progress is experienced and where this progress may be applied to the other sector, will experience, a phenomenon of de-concentration. The higher productivity will be applied in the other sector, generating a more diversified industrial environment. The other region, where the non-technological good is produced will remain non diversified and will have lower real wages.

This third case relates in a crucial way, the local nature of knowledge spillovers, to the temptation to apply the advanced technology, in the region, to the other industry. Diversification is the consequence of technological advancement in one industry, that induces pressure to innovate the process of production in other industries too, competing with existing varieties on an efficiency ground. As in each region will be produced some varieties of products and not others, we can imagine that in the technologically advanced region are concentrated the most "technology intensive" products of an industry. This story is also consistent with a "product cycle", or better 
a "process cycle" in production. When knowledge to produce some varieties more efficiently is brought in, in a region which has another technologically advanced sector, the new firms are located in that region, to benefit of the knowledge spillovers. When the particular variety becomes more standardized, its production can be moved in the other region, which remains specialized in the less technological sector. This story which in this model has a static framework has although, a dynamic flavor and as all the new geography models has important implications in the understanding of the evolution of inter-regional specialization and trade.

\subsection{Technological Lock-in}

When transport costs fall below the critical point and agglomeration is triggered, the model developed in the previous section gives us a world where production in each sector is fully concentrated in one region. This is the starting point of a phase in which technological spillovers increase total factor productivity. In this first case the potentiality for knowledge spillovers and increase in productivity are the same in the two sectors. Therefore the production function of each firm in the first region (where industry 1 is concentrated) will become:

$$
x(i)_{1}=A\left(\frac{\left(l(i)_{1}^{\beta} X_{1}^{\alpha} X_{2}^{\gamma}\right)-F}{B}\right)
$$

where A $(\geq 1)$ represents the increase in TFP due to local disembodied technological progress. The production function for firms in sector 2, concentrated in the second region becomes:

$$
x(i)_{2}=A\left(\frac{\left(l(i){ }_{2}^{\beta} X_{2}^{\alpha} X_{1}^{\gamma}\right)-F}{B}\right)
$$


The production function of good 2 in the first region and of good 1 in the second region, stays as in (3).

An increase in productivity will decrease the unitary cost to produce a good, and in our context will also decrease their price (condition (6)). This will increase real wages. The model is still symmetric, but now as A increases in each region the specific advantage of that region in producing varieties of one industry only increases. This can be seen very easily if we calculate the "temptation to spin-off" in the other industry. In this case it will be given by:

$$
\left(\frac{w_{2}}{w_{1}}\right)^{\beta \sigma}=\frac{T^{(\gamma-\alpha) \sigma}}{A^{\sigma}}\left[\frac{1+\gamma-\alpha}{2} T^{\sigma-1}+\frac{1+\alpha-\gamma}{\beta} T^{1-\sigma}\right]
$$

It is evident that, as A increases this "temptation" decreases. In particular, as transport costs are such that agglomeration is guaranteed for $\mathrm{A}=1$, technological progress will only strengthen the advantage to produce in one unique industry. The plot of equation (18) for increasing $\mathrm{A}$, for the values of the parameters as in section 3 and for transport costs $=1.4$ is shown in Figure 7.

We take transport cost $\mathrm{T}=1.1$ as reference point $(* * * *$ refer to Hummels 1998 for a justification of the level of transport costs), and we consider the evolution of real wages and industry agglomeration as function of A. Figure 8 illustrate this exercise, implying no effect of technological advancement on localization and an increase in real wages, as technology improves.

\subsection{Sector-Specific technology}

Technological spillovers may take a different form. Assuming that there is a product which is intrinsically more knowledge-intensive than the other then, within the same sector, new varieties produced in the second region may benefit of knowledge developed in the first region. The production function of sector 1 will be modified as in (16), for both regions, while the production function of good 2 will be as in (3) for 
both regions. Spillovers work for the "technology-intensive" good across regions, but as the other good does not use (or use to a lower degree) knowledge in production it will not benefit from those. In this case, starting after the catastrophic agglomeration, from a world were the production of the high-tech good is concentrated in the first region, technological growth in form of TFP growth, increases the advantage of that region in term of production efficiency. This decreases the prices of the good and increases real wages. Nevertheless the temptation to spin-off in the other sector does not arise in the technologically advanced region (nor in the other), as the production technology of the other good does not benefit from knowledge spillovers. The expression of what we called "temptation to deviate" is given exactly by (15). Therefore industries will remain concentrated in each region and there will be no change in the pattern of specialization. I plot the pattern of real wage and "temptation wage" in this case, in Figure 9. As can be seen, although technological progress increases the real wage in both regions as it decreases the unit costs of producing the technologically intensive good, it does not modify the pattern of specialization.

\subsection{Regional Spillovers}

Finally, if local spillovers across industries are important, in the sense that the technology developed locally for the highly technological industry could be used also to increase the productivity of the other industry, then increased productivity may generate a tendency towards de-concentration. This story is consistent with the findings (Henderson et al 1995, Glaeser et al 1992) that in local diverse environments cross industry externalities are very important in the production of new varieties. We represent this case as a world economy were the first region develops technological progress, as sector 1 is the most technologically dynamic, but increased productivity could be applied to the other sector as well, if developed in the same region. The production functions, for the two sectors in the first region, are given by equation (16) and (17). In the other region production functions are as (3). Intuitively this situation is one in which the region which has the technological leadership and is specialized in knowledge intensive goods, may experience the rise of some firms in the other sector 
who enjoy of productivity advantages. In particular as the technological leadership of the region increases, the temptation to adopt the innovative technologies in the other sector arises. So there is a tendency of technologically advanced regions to despecialize in order to take advantage of their productive possibilities in all sectors. The other region will remain specialized, as it will be competitive only in the sector which enjoys the agglomerating advantages. In a suggestive interpretation of this phenomenon we may say that, as the technological lead of a region increases, because of local spillovers and technological growth, that region will become the place of production of the varieties in the higher technological range of the other sector. The other region, will remain specialized in the standardized and low-tech varieties of sector 2 .

This story is illustrated in figure 10 and 11 , which represents the usual real wage-temptation wage, for the dynamic region and for the stagnant region. As it is clear technological advantage determines the tendency of the dynamic region to despecialize. For the parameters values chosen, a level of technological advantage larger than $4 \%$ will already induce the first region to de-specialize. This process, though, is not catastrophic neither necessarily complete. In fact, as the other region remains specialized, the share of workers that can profitably produce in the other sector is limited, although increasing with the technological advantage. We assume that the second region remains specialized (and we check that in fact there will be no incentive for those workers to spin-off in the other sector) and we plot the evolution of the share of workers in sector 1 as a function of A (figure 12). The tendency of the technologically advanced region to de-specialized emerges relatively early, for advantages in the TFP around 3-4\% of the total. The de-specialization, though evolves slowly and at 50\% technological advantage the first region has still $70 \%$ of the labor force concentrated in sector 1 . It seems plausible that transport costs cannot decrease without bound. In 1994 an estimate of the freight rates from US to Canada (the lowest between two countries) were around $4 \%$ of the values of the imported goods (Hummels 1998). Therefore it seems plausible to consider 5-10\% as not unreasonable levels of transport costs.

With higher transport costs the tendency to de-specialize will emerge for even lower values of technological advantage and the share of workers in the other sector 
for each technological advantage is larger. The effects are quantitatively small ${ }^{6}$. Also if we weaken the intra-industry linkages, we have that de-specialization emerges earlier. Again our simulations show that the quantitative effect is not large. Finally the results are maintained if we assume that the technological spillovers in the advanced region only improve the other sector's productivity of a fraction of the advantage in the technologically dynamic sector.

\section{Welfare Implications}

We need to be careful to draw conclusions or implications from this extremely simple model, that seems to fit the stylized fact we know about the pattern of interregional specialization. The framework that we have developed, though, allows us to have a benchmark for welfare analysis, that comes from the possibility of evaluating real wages under different assumptions. The nature of the technological spillovers is absolutely crucial for the implications of the model, not only on the specialization patterns but also on the relative welfare. If spillovers across regions within industries are prevailing, then the initial localization of the industries does not affect the welfare of regions (Figure 14). In particular, also the region that hosts the less dynamic industry will benefit from this complete specialization and the relative price of the products will move to guarantee that its wages are equal to those in the other region. The technological progress in sector 1 (concentrated in the first region) will benefit both regions. Crucially, it is the possibility of applying the technological advantage in the other sector, that will guarantee higher wages and a welfare advantage to the region where sector 1 concentrates first (Figure 13).

This confirms the idea that attracting some industries in a region is particularly beneficial if this industry has positive effects on the productivity of others. This should also imply that the best policy is to attract sectors which develop technology with general application possibilities, rather than advanced sector with a very narrow range of applications for their technology.

\footnotetext{
${ }^{6}$ We have changed transport costs to 1.4 and obtained results very similar to the one in figure 12 .
} 
In the process of concentration, driven by decreasing transport costs, there is a phase with intermediate costs, in which de-specialization is still an equilibrium, but is inefficient (i.e. is pareto-dominated by specialization). It would be profitable to move the economy out of the "dispersed case" as soon as the concentrated equilibrium is sustainable. On the other hand, in the process of de-specialization, driven by technological opportunities, the equilibrium is always efficient, as the region moves to de-specialize as soon as it is profitable.

\section{Conclusions}

This paper presents some stylized facts, which have been established by empirical and historical analysis but have not been object of particular attention by the economists. Certainly the phenomenon of international and inter-regional specialization is one of the most studied since Smith ( "the Wealth of Nations" 1776) and Ricardo ("Principles of Political Economy" 1817) first published their theories of international trade. Nevertheless only recently the economists have found a framework to understand geographical specialization and its ties to cost and demand linkages, transport costs and economies of scale. This paper considers a model that allows to understand the incentives to concentrate the production of a sector in a region, in a phase where the decrease of transport costs is the main engine of change. On the other side it gives a key to interpret de-specializations, spin-offs, and process cycles when productivity growth is the main engine of change. We assume that, for some sectors, the process of concentrating and exceeding a local critical mass, may have triggered a process of cumulating knowledge and innovation, at the local level. This means that after a "phase one" of industrial concentration it may endogenously arise a "phase 2" of industrial de-concentration, driven by technological leader regions, which diversify their production in other sectors. The ultimate test of the model must be empiric. I think that the value of this contribution is to single out an interesting mechanism that will lead to de-concentration and is based on versatility of technological innovation, region specificity and local spillovers.

The extensions that I am envisioning, in the very near future, are in the sense of more realistic representation of reality. I will introduce technological differences in the production of the two goods, making the technologically dynamic one, also skilled- 
labor intensive. I will incorporate the incentives of workers to move between region when wages differentials are very high. I am convinced that the empirical testability of the implications of the model make it a very appealing and valid tool to explore the interaction between technology, localization and specialization. 


\section{References}

Davis 1998 "The home Market, trade and industrial Structure" American Economic Review

Davis and Weinstain 1998 "Does economic Geography matter for international specialization?" mimeo Harvard University 1998

Davis, Weinstain and Shimpo 1997 "Using International and Japanese Regional data to determine the Factor Abundance theory of Trade works" American Economic Review, June

De Vries J. "European Urbanization, 1500-1800" Cambridge, Mass. Harvard University Press, 1984

Dixit and Stiglitz (1977) "Monopolistic Competition and Optimum Product Diversity" American Economic Review

Ellison and Glaeser 1997 “Geographic concentration in U.S. Manufacturing Industries: a Dartboard approach” Journal of Political Economy 1997

Fujita, Krugman and Venables 1998 “ The Spatial Economics, Cities, regions and International Trade" forthcoming

Glaeser , Kellal, Sheinkman and Shleifer.(1992) “Growth in Cities” Journal of Political Economy 1992

Henderson, Kunoco and Turner 1995 "Industrial development in cities”” Journal of Political Economy 1995

Hummels D. 1998 “Towards a Geography of Trade Costs” mimeo University of Chicago. 
Jaffe, Henderson and Trajtenberg (1992) “Geographic localisation of knowledge spillovers as evidenced by Patent citation" Quarterly Journal of Economics 1992

Krugman (1979) "A model of innovation, technology transfer, and the world distribution of income" Journal of Political Economy 1979

Krugman 1991a "Increasing Returns and Economic Geography” Journal of Political Economy 1991

Krugman 1991b "Geography and Trade” MIT Press.

Krugman and Venables 1995 "Globalization and the Inequaltity of Nations" Quarterly Journal of Economics 1995

Krugman andVenables (1996) "Integration, Specialization and Adjustment” European Economic Review 1996

Kim S. 1995 "Expansion of Markets and the Geographic Distribution of Economic Activities: The Trend in U.S. Regional Manufacturing Structure, 1860-1987” Quarterly Journal of economics 1995

Marshall A. 1920 "Principles of Economics” New York Macmillian

Paci and Usai 1998 “Technological Enclaves and Industrial districts. An Analysis of the regional distribution of Innovative activity in Europe" Crenos Working Paper

Peri 1998 "Human Capital Externalities in U.S. Cities" Fondazione Eni Working Paper

Puga D. and A. Venables 1997 "The Spread of Industry, Spatial Agglomeration I economic Development” CEPR Working Paper \# 1354 


\section{Appendix A}

311 FOOD $(311+312)$

313 BEVERAGE

314 TOBACCO

321 TEXTILE

322 CLOTHING (EXCL. FOOTWEAR)

323 LEATHER (EXCEPT FOOTWEAR)

324 FOOTWEAR

330 WOOD AND WOOD PRODUCTS

340 PAPER AND PAPER PRODUCTS

341 PAPER PRODUCTS

342 PRINTING, PUBLISHING AND ALLIED

351 CHEMICALS AND CHEMICAL PRODUCTS $(351+352)$

353 PETROLEUM REFINERIES

360 NON-METALLIC MINERAL PRODUCTS

ISIC 362)

362 GLASS AND GLASS PRODUCTS

371 IRON AND STEEL

372 NON-FERROUS METAL

381 METAL PRODUCTS

382 MACHINERY (EXCLUDING ELECTRICAL)

383 ELECTRICAL MACHINERY

384 TRANSPORT EQUIPMENT

400 ELECTRICITY, GAS AND WATER 


\section{Appendix 2}

Values of Parameters used in the simulations to draw the figures:

Figure 1: $\alpha=0.4, \gamma=0.1, \beta=0.5, \sigma=5, T=1.3$

Figure 2: $\alpha=0.4, \gamma=0.1, \beta=0.5, \sigma=5, T=1.45$

Figure 3: $\alpha=0.4, \gamma=0.1, \beta=0.5, \sigma=5, T=1.6$

Figure 4: $\alpha=0.4, \gamma=0.1, \beta=0.5, \sigma=5$

Figure 5: $\alpha=0.4, \gamma=0.1, \beta=0.5, \sigma=5$

Figure 6: $\alpha=0.4, \gamma=0.1, \beta=0.5, \sigma=5$

Figure 7: $\alpha=0.4, \gamma=0.1, \beta=0.5, \sigma=5, T=1.1$.

Figure 8: $\alpha=0.4, \gamma=0.1, \beta=0.5, \sigma=5, \mathrm{~T}=1.1$.

Figure 9: $\alpha=0.4, \gamma=0.1, \beta=0.5, \sigma=5, T=1.1$.

Figure 10: $\alpha=0.4, \gamma=0.1, \beta=0.5, \sigma=5, \mathrm{~T}=1.1$.

Figure 11: $\alpha=0.4, \gamma=0.1, \beta=0.5, \sigma=5, T=1.1$.

Figure 12: $\alpha=0.4, \gamma=0.1, \beta=0.5, \sigma=5, \mathrm{~T}=1.1$.

Figure 13: $\alpha=0.4, \gamma=0.1, \beta=0.5, \sigma=5, T=1.1, \theta=0.8$ 
Figure I (Kim 1995 QJE page 891 Figure I)

Figure II (Kim QJE 1995 page 895 figure II) 


\section{Figure III}
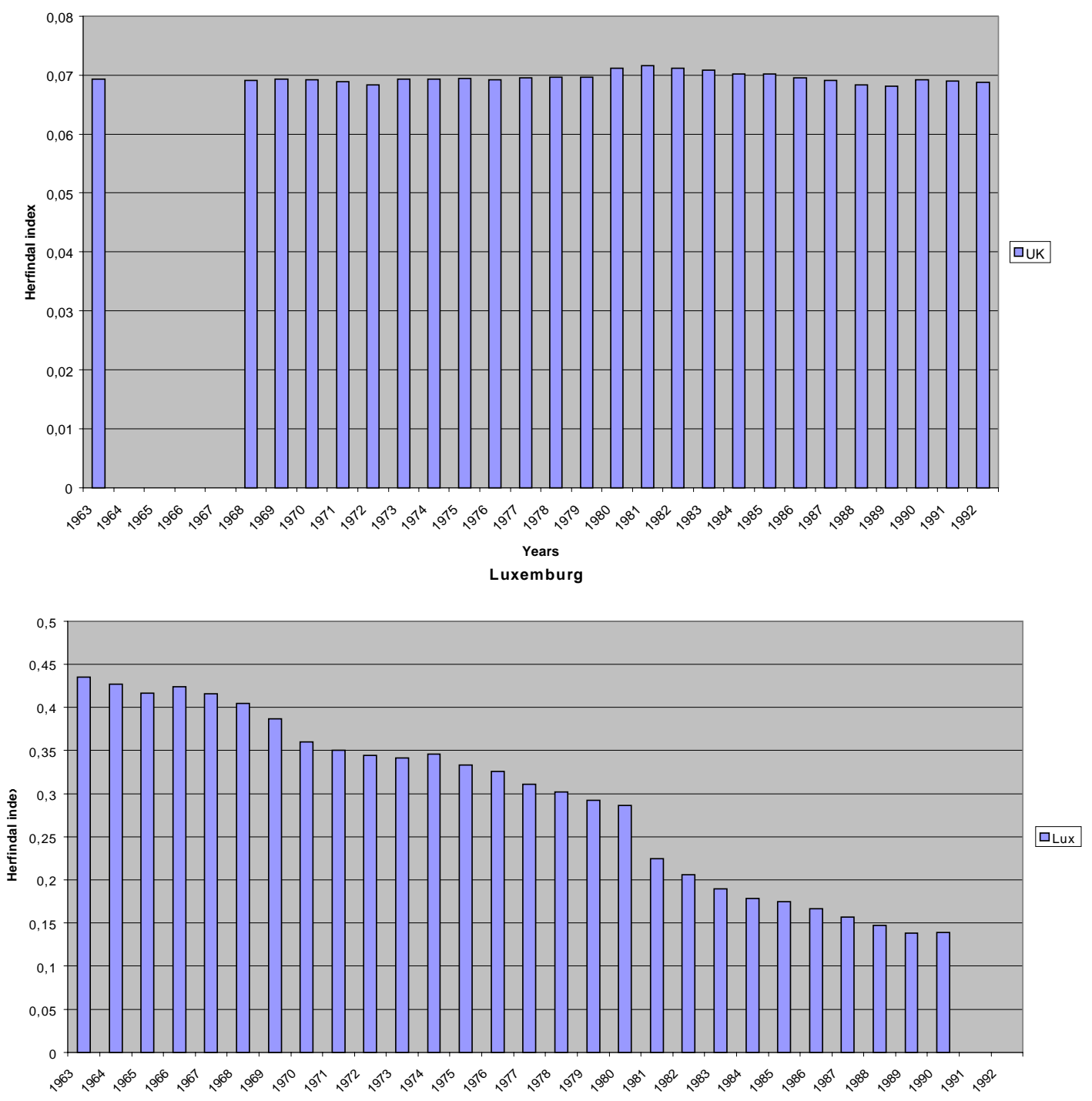

Portugal
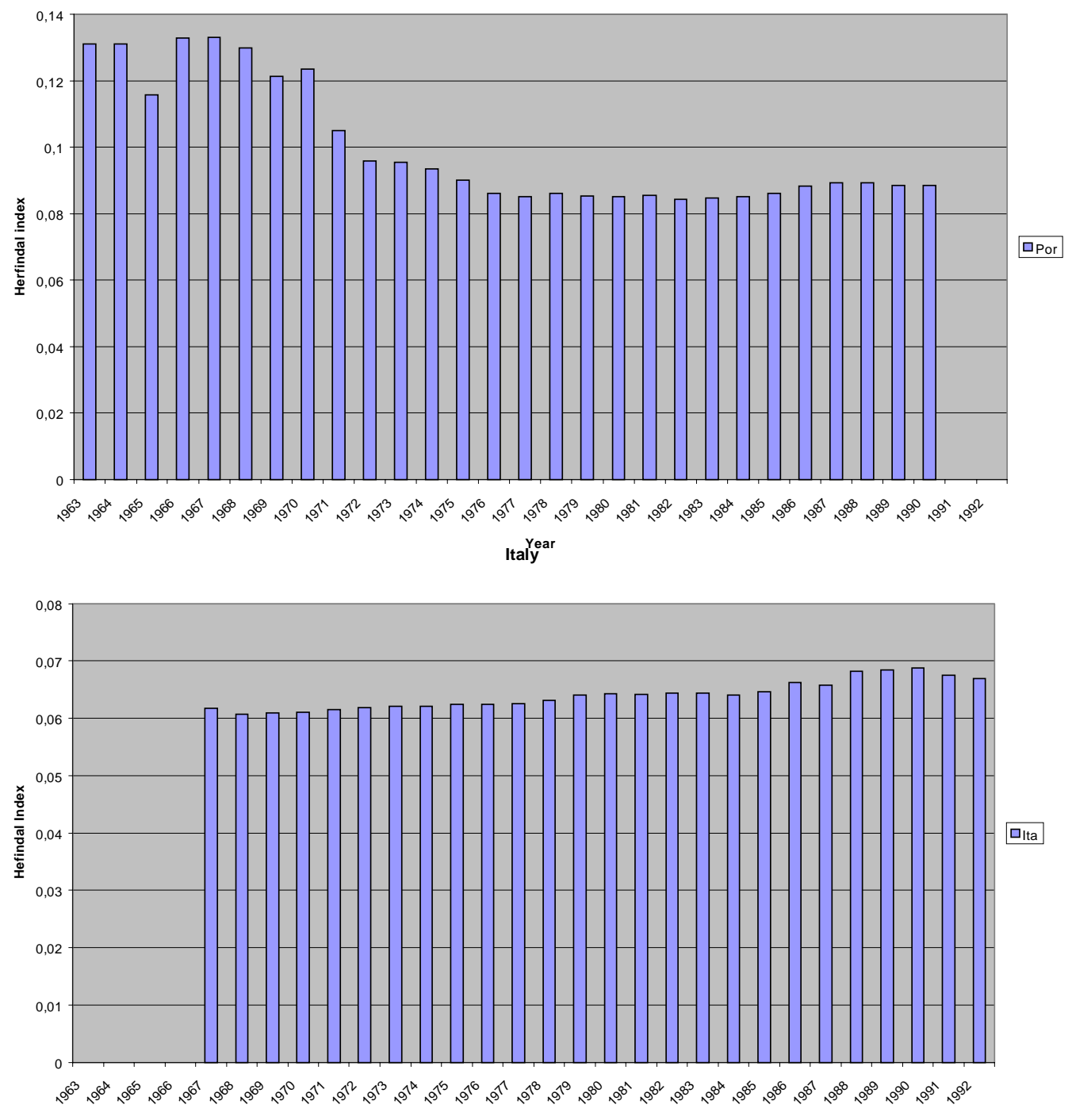

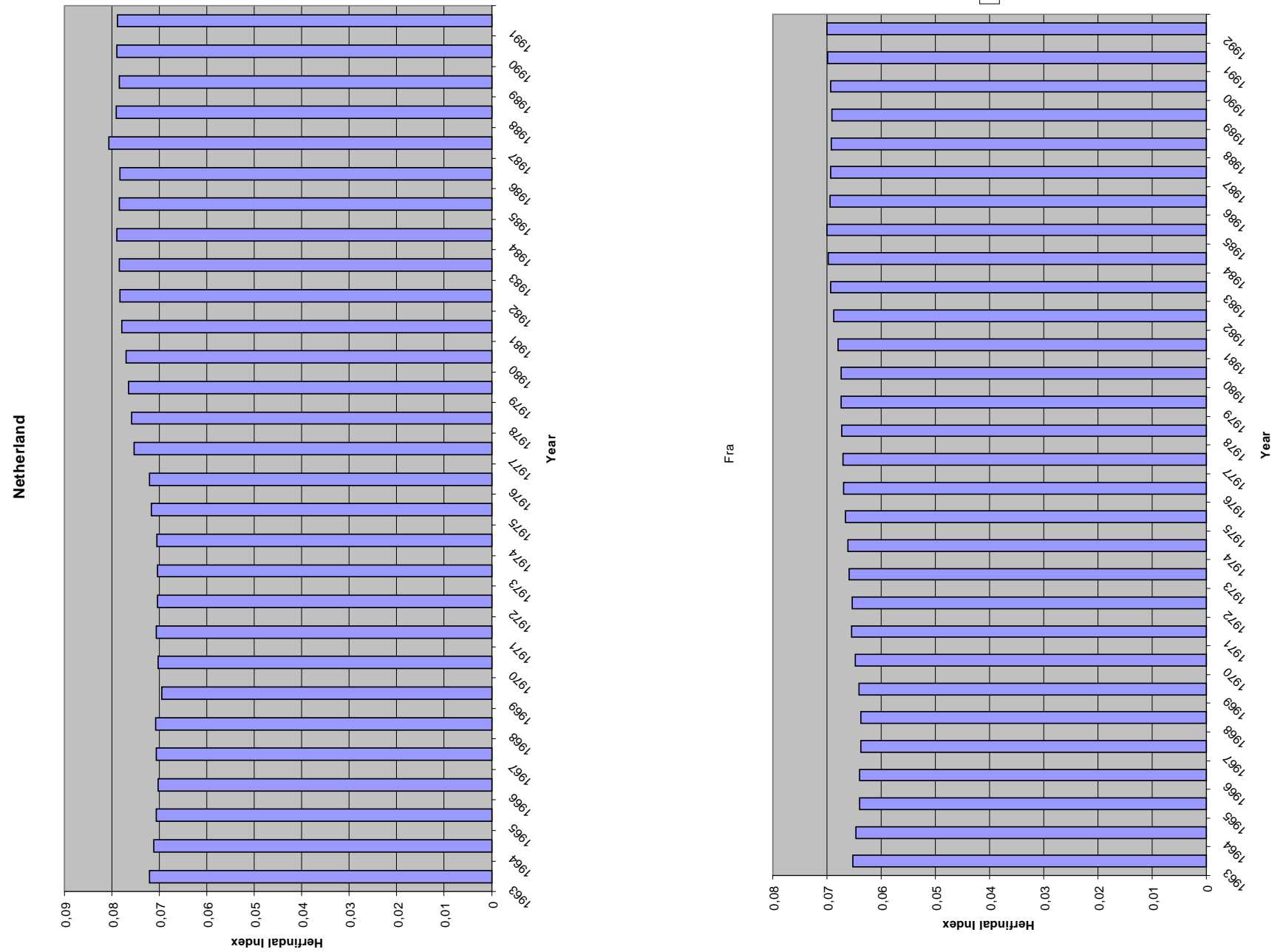

픔
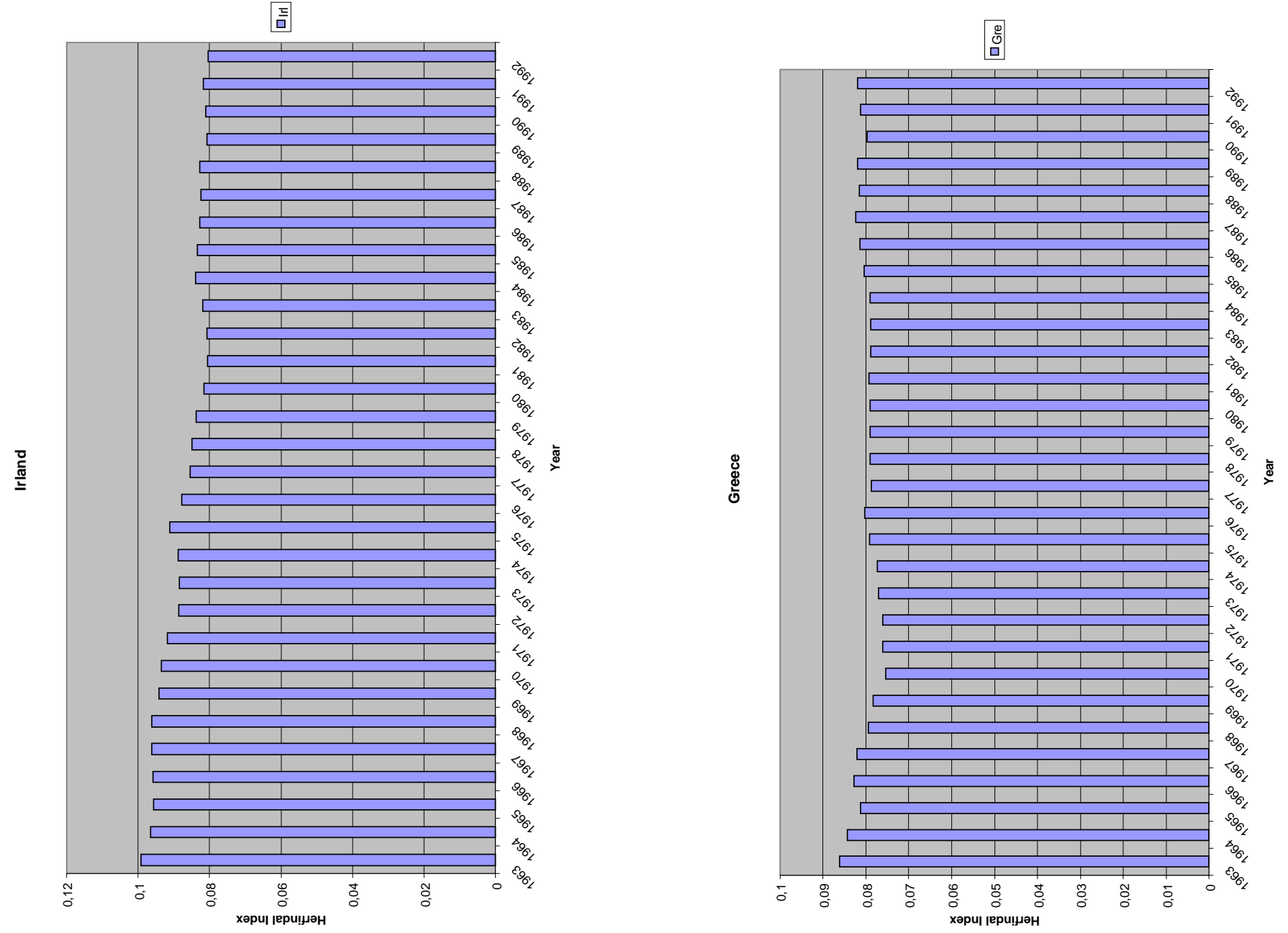

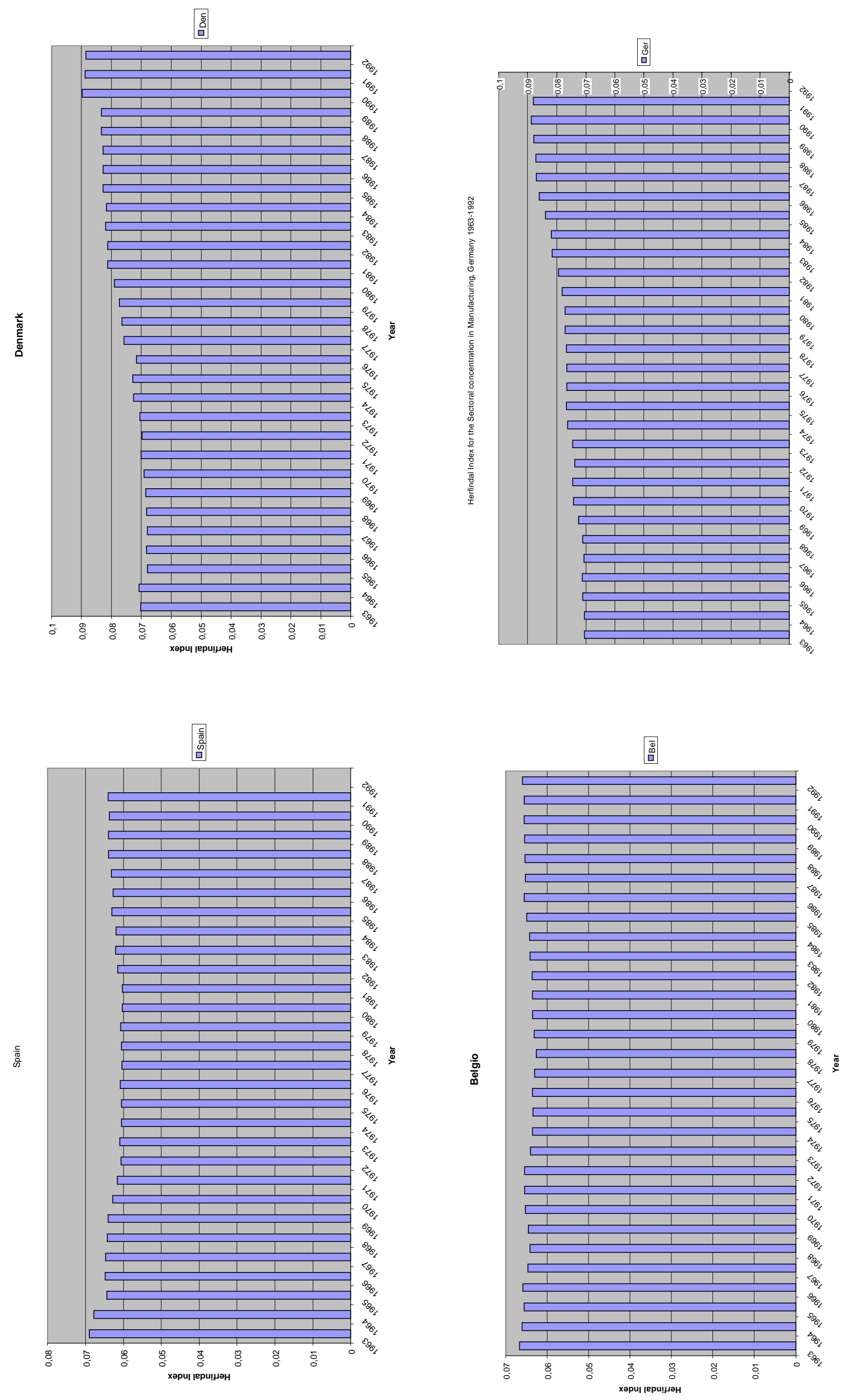
Figure IV

EU 11 average

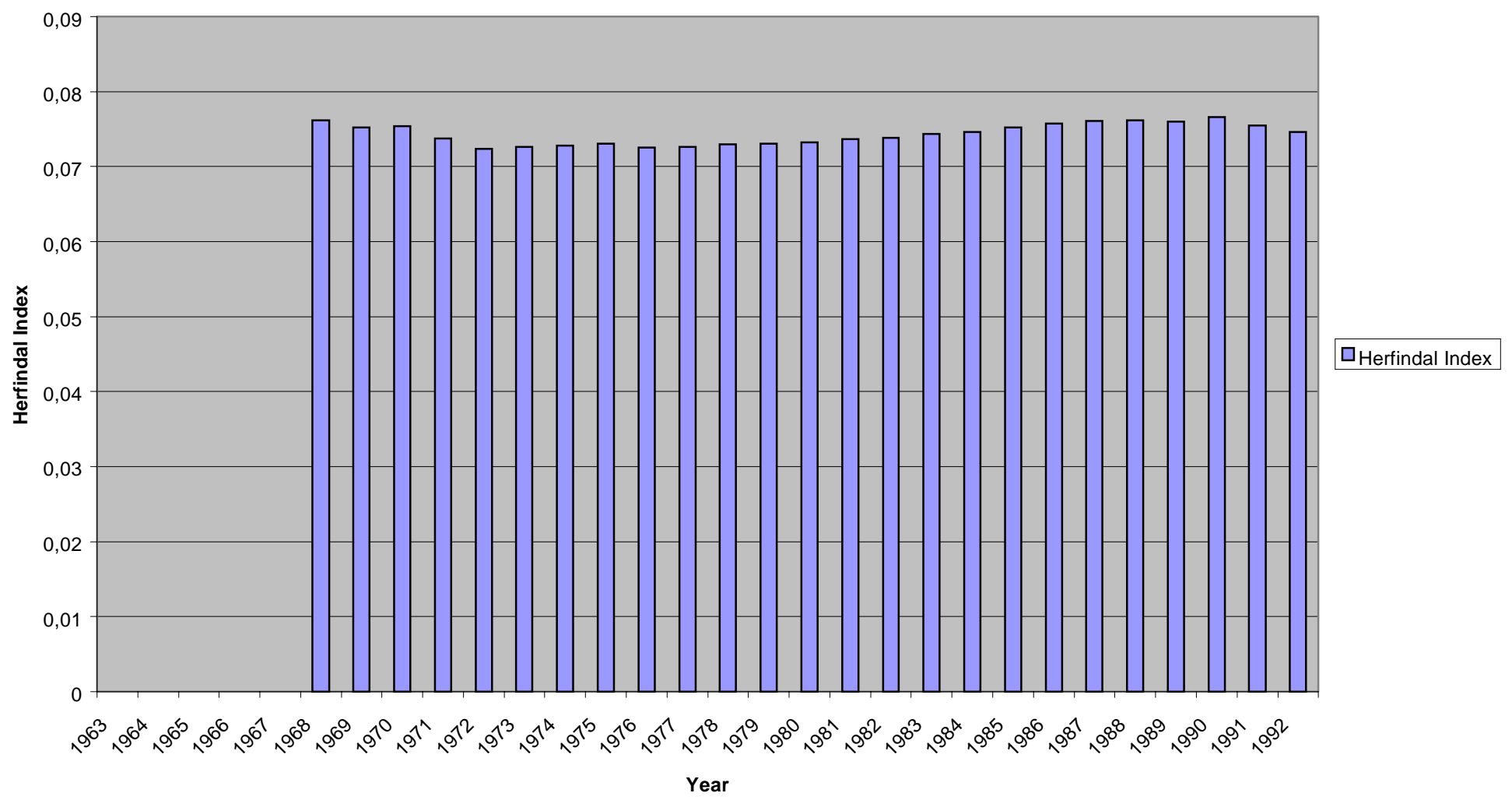



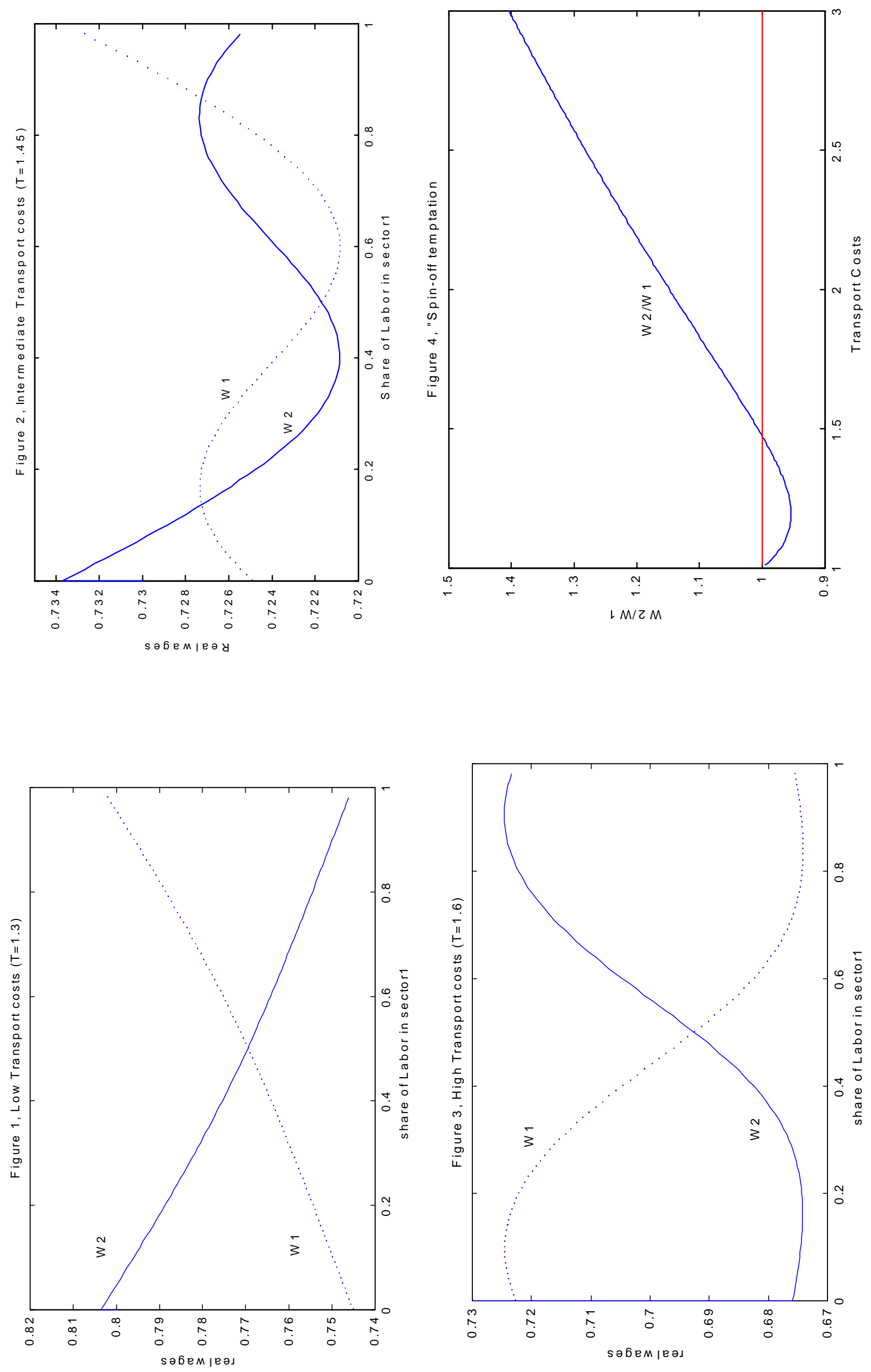

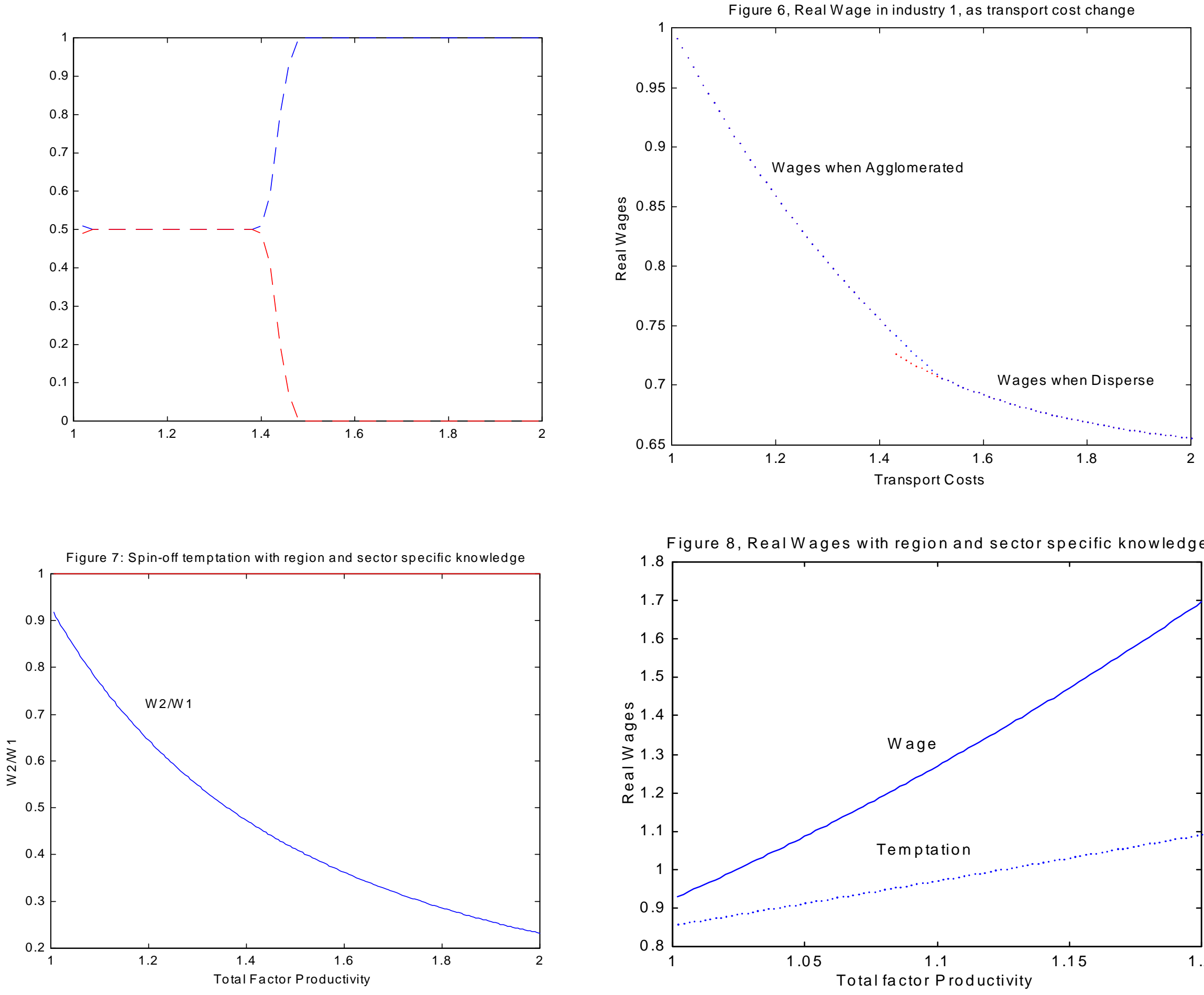

Figure 8 , Real Wages with region and sector specific knowledge

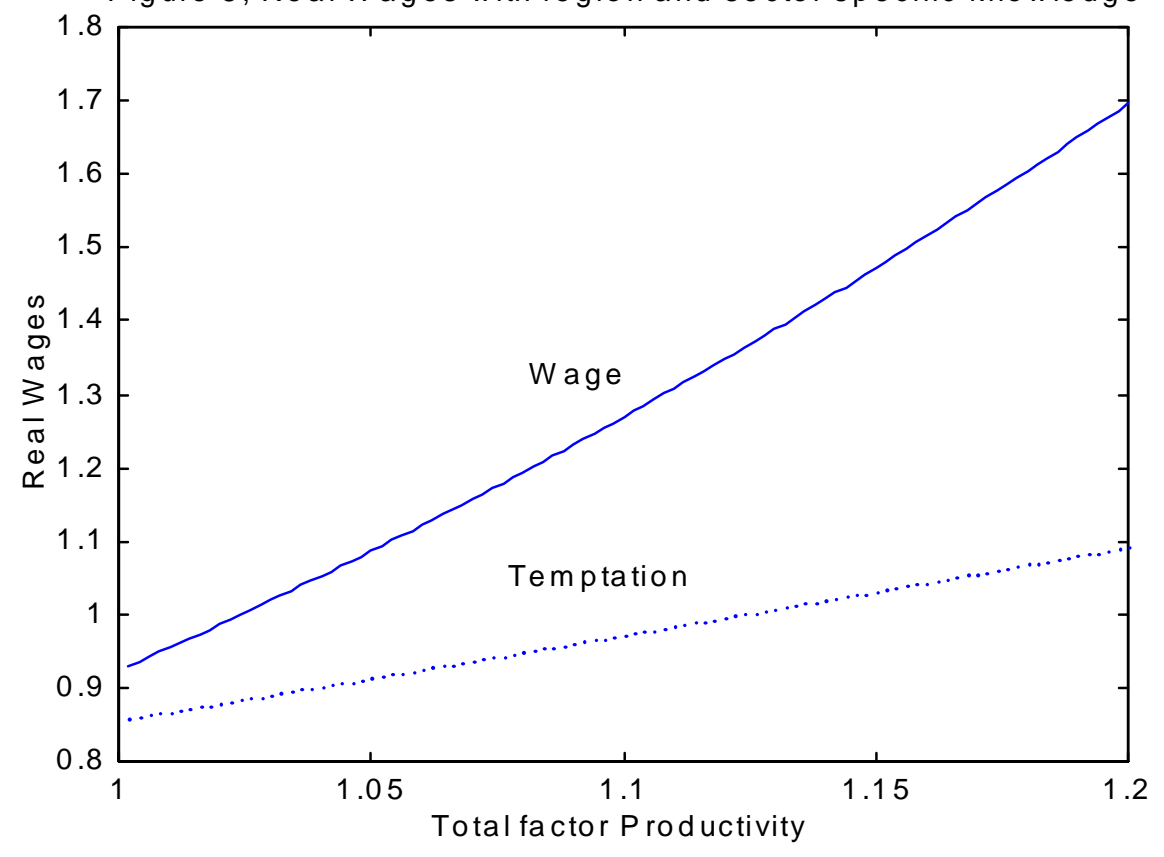



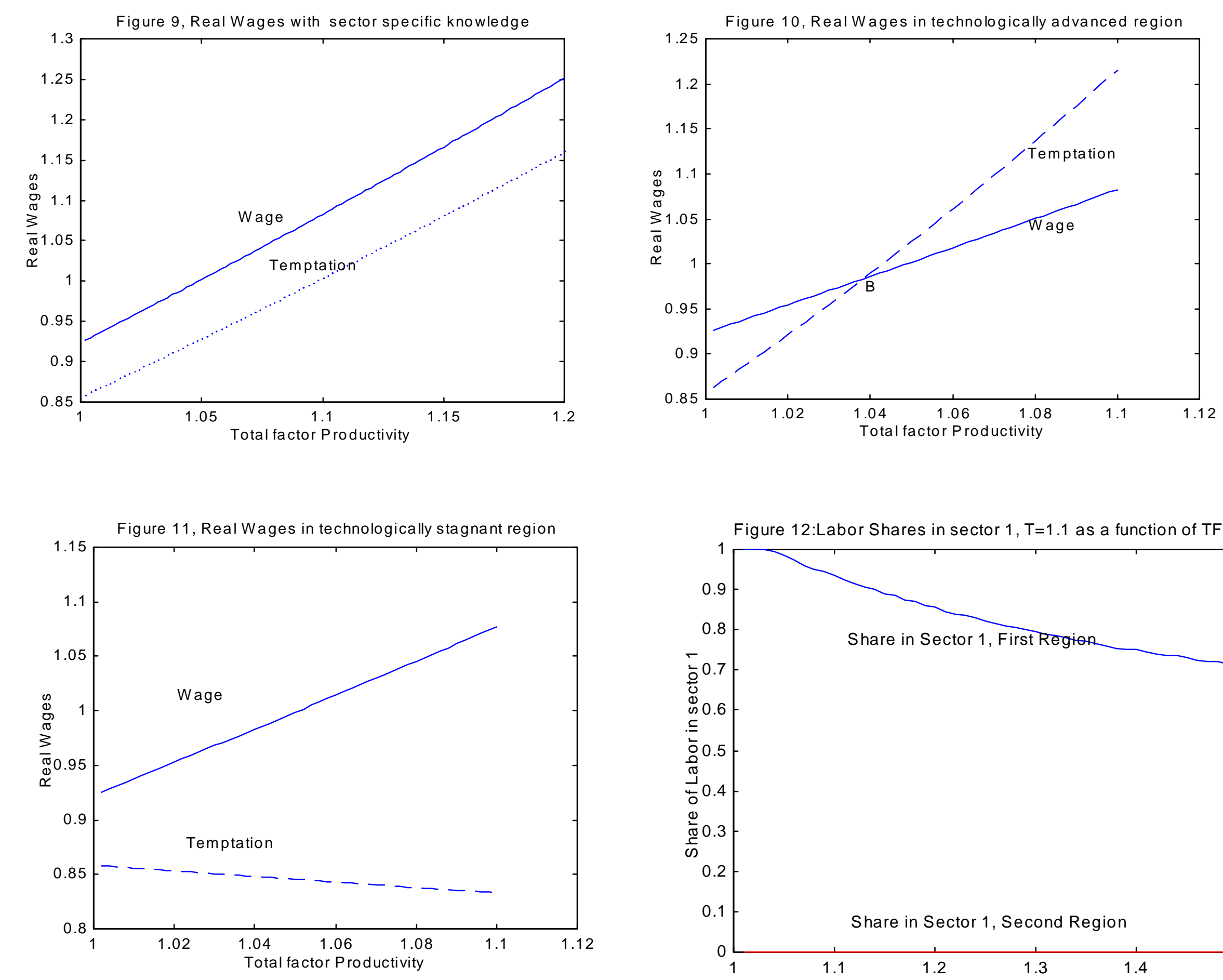

Figure 12:Labor Shares in sector $1, T=1.1$ as a function of TFP

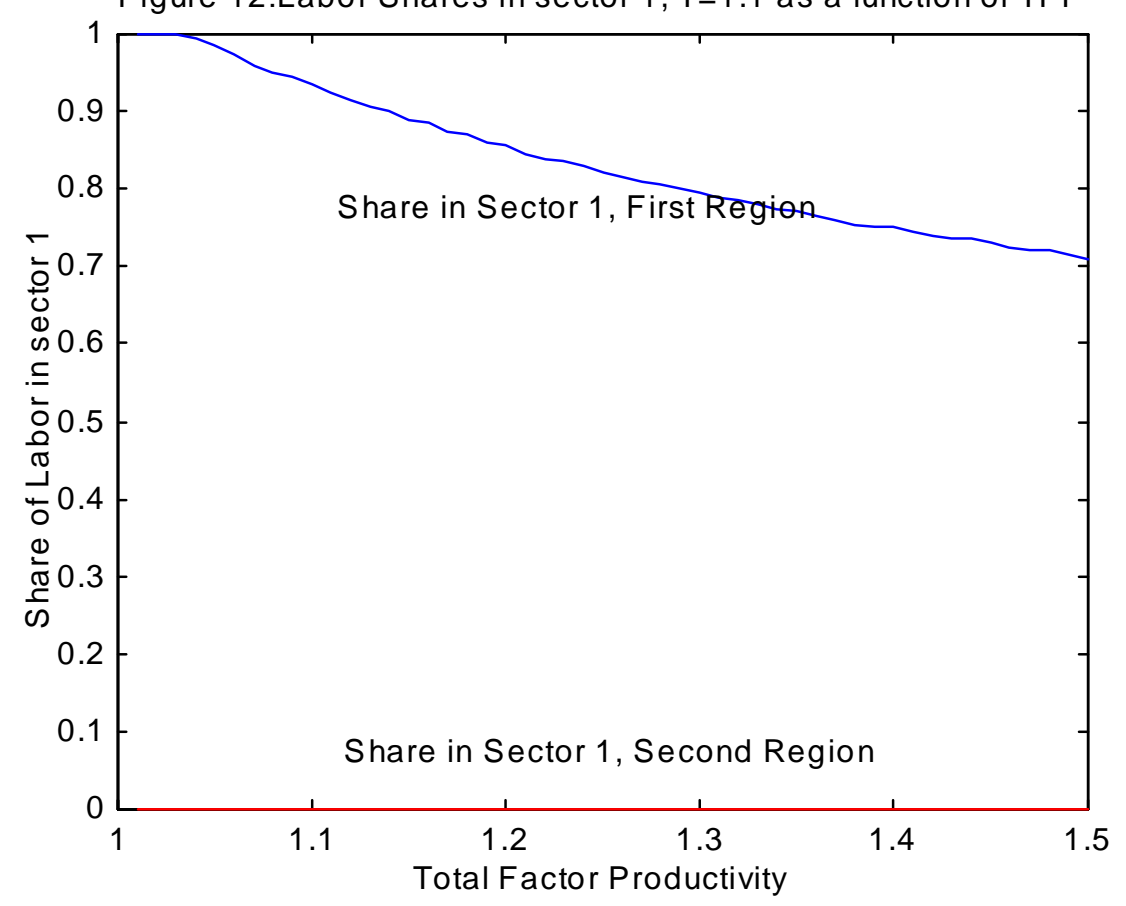



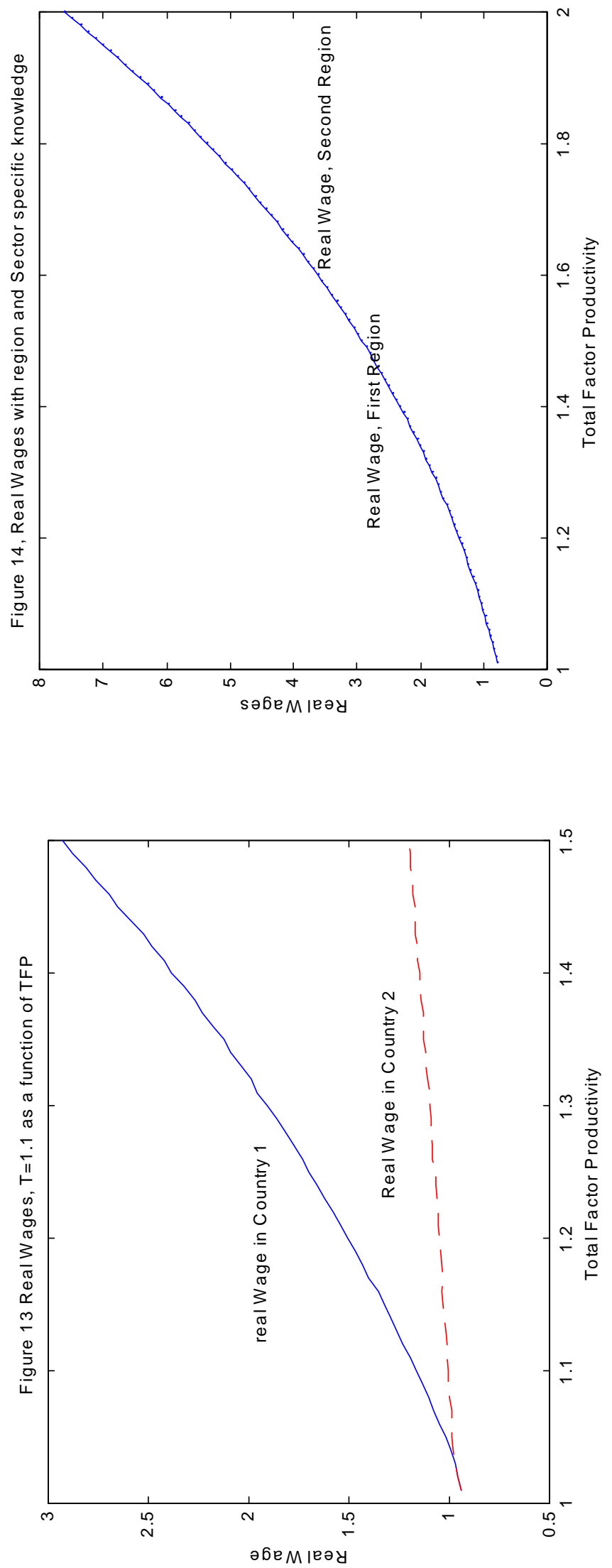